\title{
METODE EXPONENTIAL SMOOTHING EVENT BASED (ESEB) DAN METODE WINTER'S EXPONENTIAL SMOOTHING (WES) UNTUK PERAMALAN JUMLAH PENUMPANG TIBA DI PELABUHAN PENYEBERANGAN GORONTALO \\ : https://doi.org/10.30598/barekengvol13iss3pp199-204ar935
}

\section{Exponential Smoothing Event Based (ESEB) Method And Winter's Exponential Smoothing (WES) Method For Forecasting Arrival Passengers In Gorontalo Crossing Port}

\author{
Muhammad Rezky Friesta Payu ${ }^{1 *}$, Nurwan ${ }^{2}$ \\ 1,2 Jurusan Matematika Fakultas Matematika dan Ilmu Pengetahuan Alam, Universitas Negeri Gorontalo
} Jln. Jenderal Sudirman No. 6, Gorontalo, Indonesia e-mail: ${ }^{1}$ rezky@ung.ac.id ; ${ }^{2}$ nurwan@ung.ac.id;

Corresponding Author*

\begin{abstract}
Abstrak
Peramalan jumlah penumpang bisa menjadi pertimbangan pengelola Pelabuhan Penyeberangan Gorontalo terkait penyedian tiket. Jumlah penumpang bisa dipengaruhi oleh musiman ataupun special event tertentu. Untuk melihat special event yang berpengaruh pada jumlah penumpang yang tiba di Pelabuhan Penyeberangan Gorontalo maka metode peramalan yang digunakan adalah metode Exponential Smoothing Event Based (ESEB). Pengaruh musiman dapat diketahui melalui pola data historis dan menggunakan metode Winter's Exponential Smoothing (WES). Setelah dibandingkan, metode ESEB merupakan metode yang lebih baik dalam meramalkan jumlah penumpang yang tiba di Pelabuhan Penyeberangan Gorontalo karena memiliki nilai MAPE yang lebih kecil dibandingkan metode WES
\end{abstract}

Kata Kunci : Penumpang tiba, special event, exponential smoothing event based, winter's exponential smoothing, MAPE.

\begin{abstract}
Forecasting the number of passengers can be a consideration for managers of Gorontalo Crossing Port regarding the provision of tickets. The number of passengers can be influenced by certain seasonal or special events. To see the special events that affect the number of passengers arriving at Gorontalo Crossing Port, the forecasting method used is the Exponential Smoothing Event Based (ESEB) method. The seasonal influences can be known through historical data patterns and using the Winter's Exponential Smoothing (WES) method. After compared, the ESEB method is a better method of forecasting the number of arriving passengers at Gorontalo Crossing Port because it has a smaller MAPE value than the WES method.
\end{abstract}

Keywords: Arriving passengers, special event, exponential smoothing event based, winter's exponential smoothing, MAPE 


\section{PENDAHULUAN}

Pelabuhan Penyeberangan Gorontalo merupakan salah satu dari 3 (tiga) pelabuhan penyeberangan yang ada di Provinsi Gorontalo yakni Pelabuhan Penyeberangan Gorontalo, Pelabuhan Penyeberangan Marisa dan Pelabuhan Penyeberangan Gorontalo Utara (yang saat ini masih dikembangkan). Ada dua alur penyeberangan yang dilayani di Pelabuhan Penyeberangan Gorontalo, yakni alur pelayaran Gorontalo Pagimana dan Gorontalo - Wakai [1].

Lonjakan penumpang biasanya terjadi pada hari-hari tertentu misalnya Hari Raya Keagamaan seperti Hari Raya Paskah [2], Hari Raya Idul Fitri [3], Hari Raya Idul Adha [4], serta Hari Raya Natal [5]. Waktuwaktu tersebut selanjutnya dalam kajian ini disebut special event. Lonjakan penumpang ini biasanya menimbulkan beberapa masalah. Diantaranya yakni terlantarnya penumpang akibat keterbatasan tiket dan juga kelebihan muatan akibat kapasitas yang dipaksakan. Ini berbahaya karena bisa menimbulkan kecelakaan [6].

Oleh karena data jumlah penumpang merupakan data time series yang dikumpulkan setiap bulan, maka masalah tersebut dapat diatasi dengan metode peramalan time series diantaranya metode event based. Metode Event Based menyarakan bahwa ada fluktuasi yang signifikan pada data dan terjadi pada waktuwaktu tertentu. Pada data jumlah penumpang terdapat fluktuasi yang signifikan, ini bisa diketahui dari adanya indikasi lonjakan penumpang dan lonjakan tersebut terjadi pada waktu-waktu tertentu. Oleh karena itu, dengan metode event based bisa diketahui ramalan jumlah penumpang kapal di Pelabuhan Penyeberangan Gorontalo pada saat terjadi lonjakan karena special event tersebut. Pada penelitian ini, akan digunakan salah satu metode event based yaitu metode Exponential Smoothing Event Based (ESEB).

Selain metode Event Based, metode lain yang digunakan adalah metode Winter's Exponential Smoothing. Syaratnya, bahwa data harus mengandung pengaruh musiman, dan data jumlah penumpang Pelabuhan Penyeberangan Gorontalo dipengaruhi oleh musiman. Data yang akan digunakan dalam penelitian ini adalah data Jumlah Penumpang yang tiba di Pelabuhan Penyeberangan Gorontalo dari bulan Januari 2015 hingga bulan Desember 2018. Pengujian ketepatan peramalan menggunakan Mean Absolute Percentage Error (MAPE).

\section{METODE PENELITIAN}

\subsection{Metode Exponential Smoothing Event Based}

Metode Exponential Smoothing Event Based adalah metode peramalan berdasarkan special event pada periode tertentu berdasarkan peramalan single exponential smoothing, sehingga yang pertama kali dilakukan adalah melakukan peramalan dengan menggunakan metode single exponential smoothing dengan persamaan berikut [7].

$$
F_{t+1}=\alpha X_{t}+(1-\alpha) F_{t}
$$

dengan,

$$
\begin{array}{ll}
F_{t+1} & : \text { Peramalan pada periode } t+1 \\
\alpha & \text { : Konstanta pemulusan }(0<\alpha<1) \\
X_{t} & \text { : Data aktual pada periode } t \\
F_{t} & : \text { Peramalan pada periode } t
\end{array}
$$

Setelah itu dihitung nilai Indeks Event pada periode yang memuat special event, dengan menggunakan persamaan berikut [8].

$$
I_{t}=\frac{X_{t}}{F_{t}}
$$

dengan $I_{t}$ adalah Indeks event pada periode $t$ yang memuat special event.

Kemudian nilai Indeks Event dirata-ratakan untuk masing-masing special event untuk mendapatkan nilai Grup Indeks. Grup Indeks digunakan sebagai faktor pengali. Setelah didapatkan faktor pengali, dilakukan peramalan $E S E B$ dengan menggunakan persamaan sebagai berikut [8]:

$$
P_{t+1}=G_{+1}\left[\alpha X_{t}+(1-\alpha) F_{t}\right]
$$


dengan,

$P_{t+1} \quad:$ Peramalan dengan indeks event pada periode $t+1$

$G_{t+1} \quad:$ Grup indeks pada periode $t+1$

$\alpha \quad$ : Konstanta pemulusan $(0<\alpha<1)$

\subsection{Metode Winter's Exponential Smoothing}

Metode Winter's Exponential Smoothing didasarkan atas tiga persamaan pemulusan, yaitu satu untuk stasioner, satu untuk trend, dan satu untuk musiman [9]. Adapun empat persamaan yang digunakan untuk metode Winter's Exponential Smoothing (multiplicative) adalah sebagai berikut [7]:

\section{1) Pemulusan Keseluruhan}

$$
L_{t}=\alpha \frac{X_{t}}{s_{t-s}}+(1-\alpha)\left(L_{t-1}+T_{t-1}\right)
$$

dengan,

$L_{t} \quad:$ Pemulusan keseluruhan $t$

$\alpha \quad:$ Konstanta pemulusan $(0<\alpha<1)$

$X_{t} \quad:$ Data aktual pada periode $t$

$L_{t-1} \quad:$ Pemulusan keseluruhan $t-1$

$T_{t-1} \quad:$ Pemulusan trend pada $t-1$

2) Pemulusan Trend

$$
T_{t}=\gamma\left(L_{t}-L_{t-1}\right)+(1-\gamma) T_{t-1}
$$

dengan,

$T_{t} \quad:$ Pemulusan trend $t$

$\gamma \quad:$ Konstanta pemulusan trend $(0<\gamma<1)$

$L_{t} \quad:$ Pemulusan keseluruhan $t$

$L_{t-1} \quad$ : Pemulusan keseluruhan $t-1$

$T_{t-1} \quad:$ Pemulusan trend pada $t-1$

\section{3) Pemulusan Musiman}

$$
S_{t}=\beta \frac{X_{t}}{L_{t}}+(1-\beta) S_{t-s}
$$

dengan,

$\begin{array}{ll}S_{t} & : \text { Pemulusan musiman } t \\ \beta & : \text { Konstanta pemulusan musiman }(0<\beta<1) \\ X_{t} & \text { : Data aktual pada periode } t \\ L_{t} & \text { : Pemulusan keseluruhan } t \\ S_{t-S} & : \text { Pemulusan musiman } t-s\end{array}$

\section{4) Peramalan untuk $p$ periode}

$$
F_{t+p}=\left(L_{t}+p T_{t}\right) S_{t-s+p}
$$

dengan,

$\begin{array}{ll}F_{t+p} & : \text { Peramalan pada periode } t+p \\ L_{t} & : \text { Pemulusan keseluruhan } t \\ p & : \text { Panjang periode peramalan } \\ T_{t} & : \text { Pemulusan trend } t \\ S_{t-S+p} & : \text { Pemulusan musiman } t-s+p\end{array}$

Untuk melakukan peramalan dengan menggunakan metode Winter's Exponential Smoothing, dibutuhkan beberapa nilai awal. Ada beberapa cara menentukan nilai awal yang telah ditetapkan, antara lain [10]: 


\subsection{Ketepatan Peramalan}

$$
\begin{aligned}
& L_{t}=\frac{1}{t}\left(X_{1}+X_{2}+\cdots+X_{t}\right) \\
& T_{t}=\frac{1}{t}\left(\frac{X_{t+1}-X_{1}}{t}+\frac{X_{t+2}-X_{2}}{t}+\cdots+\frac{X_{t+l}-X_{l}}{t}\right) \\
& S_{t}=X_{t}-L_{t}
\end{aligned}
$$

Kriteria yang dapat digunakan dalam memilih model terbaik antara lain kriteria In-sample dan Outsample. In-sample (yakni data 2015-2017) digunakan untuk pembentukan model dan Out-sample (yakni data 2018) akan digunakan untuk memeriksa ketepatan model [11]. Untuk menguji ketepatan peramalan maka akan digunakan nilai Mean Absolute Percentage Error (MAPE) dengan persamaan sebagai berikut [9]:

$$
M A P E=\frac{1}{n} \sum_{t=1}^{n} \frac{\left|X_{t}-F_{t}\right|}{\left|X_{t}\right|}
$$

dengan,
$X_{t} \quad$ : Data aktual pada periode $t$
$F_{t} \quad:$ Peramalan pada periode $t$
$n \quad$ : Periode waktu

Peramalan akan sangat baik jika nilai $M A P E<10 \%$ dan baik jika nilai $M A P E<20 \%$.

\section{HASIL DAN PEMBAHASAN}

\subsection{Plot Data}

Data yang digunakan adalah data jumlah penumpang yang tiba di Pelabuhan Penyeberangan Gorontalo dari bulan Januari 2015 sampai bulan Desember 2018. Sebagai perbandingan data aktual dan hasil ramalan, maka akan digunakan data tahun 2018.

Berikut adalah plot data historis jumlah penumpang pelabuhan penyeberangan Gorontalo dari Januari 2015 - Desember 2018:

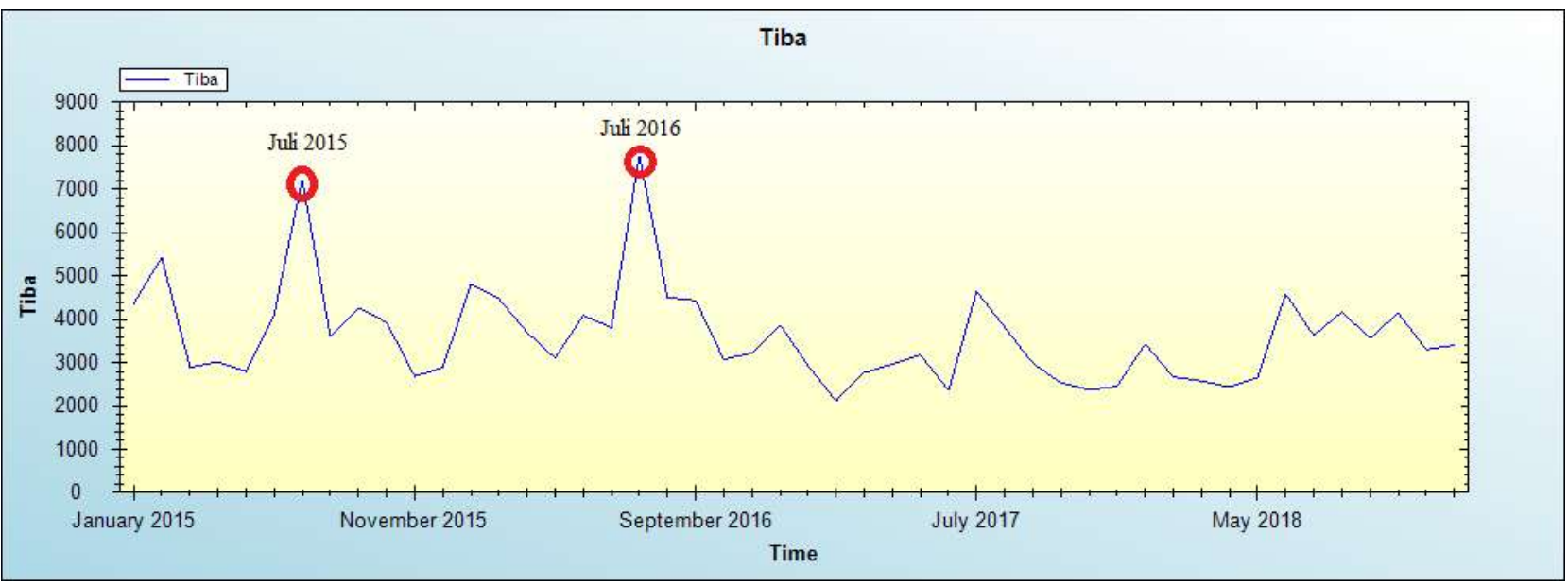

Gambar 1. Plot Data Jumlah Penumpang Tiba

(Sumber Data: Dinas Perhubungan Provinsi Gorontalo)

Special event berupa Hari Raya Idul Fitri berpengaruh pada jumlah penumpang yang tiba. Hal ini terlihat pada Gambar 1 yang menunjukkan adanya kenaikan signifikan pada bulan Juli 2015 dan Juli 2016. Jumlah penumpang tiba yang tertinggi terjadi pada Juli 2016 sedangkan yang terendah terjadi pada Maret 2017.

Special event yang berpengaruh dapat diketahui dari nilai indeks event $>1$. Nilai indeks event dapat dihitung menggunakan persamaan 2 dengan bantuan aplikasi Apache Open Office. Indeks event hanya dihitung pada bulan-bulan yang memuat special event seperti Hari Raya Paskah, Hari Raya Idul Fitri, Hari 
Raya Idul Adha dan Hari Raya Natal. Setelah dihitung nilai indeks event masing-masing special event setiap tahun, kemudian dirata-ratakan untuk mendapatkan nilai Grup Indeks.

Tabel 1. Nilai Indeks Event dan Grup Indeks

\begin{tabular}{|llll|}
\hline Special Event & Waktu & Indeks Event & Grup Indeks \\
\hline \multirow{3}{*}{ Hari Raya Paskah } & April 2015 & 0.7288 & \\
& Maret 2016 & 0.9092 & 0.8704 \\
& April 2017 & 0.9733 & \\
& Juli 2015 & 1.9596 & 1.5884 \\
Hari Raya Idul Fitri & Juli 2016 & 2.0374 & \\
& Juni 2017 & 0.7681 & 1.0024 \\
& September 2015 & 0.9596 & \\
Hari Raya Natal & September 2016 & 0.9135 & 0.8671 \\
& Agustus 2017 & 1.1242 & \\
\hline
\end{tabular}

Dari indeks ESEB pada Tabel 1, dapat diketahui bahwa special event yang berpengaruh pada jumlah penumpang tiba adalah Hari Raya Idul Fitri Tahun 2015, Hari Raya Idul Fitri Tahun 2016 dan Hari Raya Idul Adha tahun 2017. Namun, secara keseluruhan special event yang berpengaruh adalah Hari Raya Idul Fitri dan Hari Raya Idul Adha. Ini terlihat dari nilai Grup Indeks yang lebih dari 1.

\subsection{Ukuran Ketepatan}

Berikut ukuran ketepatan peramalan dengan menggunakan MAPE:

Tabel 2. Nilai MAPE

\begin{tabular}{|ccc|}
\hline Ukuran Ketepatan & $\begin{array}{c}\text { Metode Exponential Smoothing Event } \\
\text { Based }\end{array}$ & $\begin{array}{c}\text { Metode Winter's Exponential } \\
\text { Smoothing }\end{array}$ \\
\hline Nilai MAPE & $19,5916 \%$ & $19,7141 \%$ \\
\hline
\end{tabular}

Dari Tabel 2 tersebut, terlihat bahwa nilai MAPE terkecil adalah metode ESEB, sehingga dapat dikatakan bahwa metode $E S E B$ lebih baik digunakan dalam meramalkan jumlah penumpang yang Tiba di Pelabuhan Penyeberangan Gorontalo dari pada metode WES.

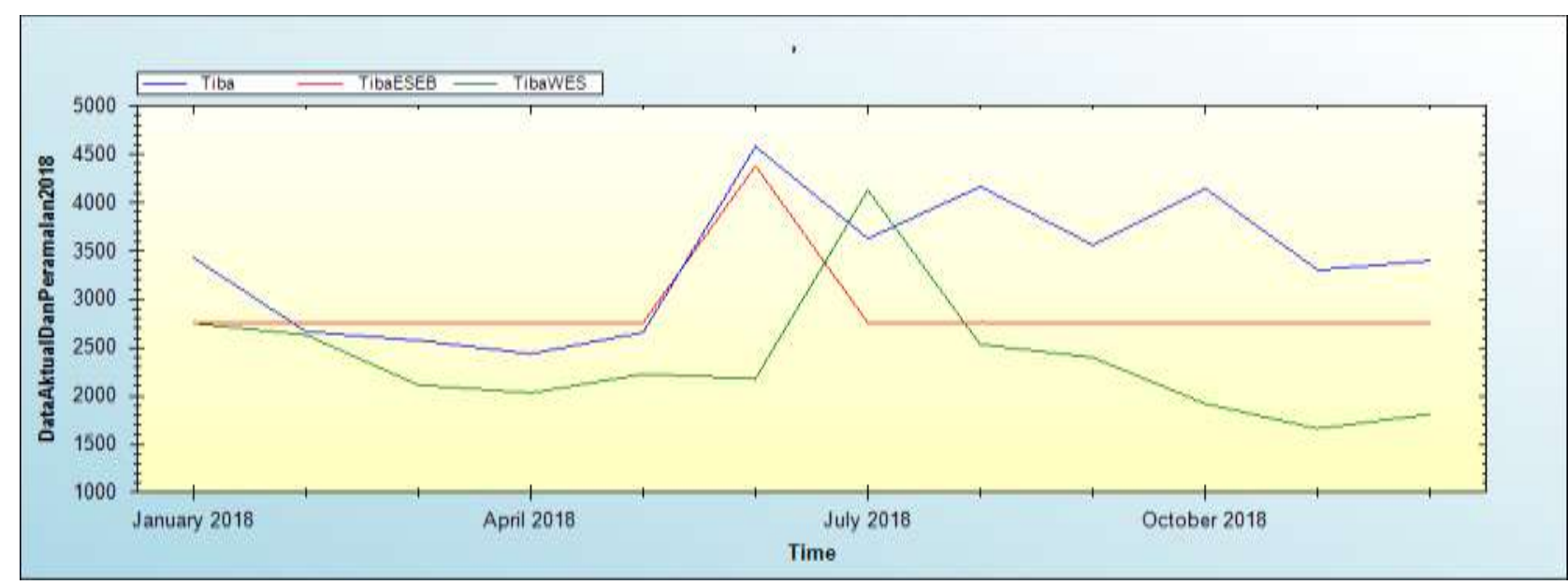

Gambar 2. Grafik Perbandingan Data Peramalan ESEB dan WES terhadap Data Aktual 2018. (Sumber Data: Dinas Perhubungan Provinsi Gorontalo)

Jika diamati dari hasil penyajian grafik tersebut, dapat diamati bahwa peramalan menggunakan metode $E S E B$ cenderung mendekati nilai data aktual bila dibandingkan dengan metode peramalan WES. 


\subsection{Perbandingan Model ESEB dan WES}

1. Model untuk peramalan ESEB adalah sebagai berikut:

Peramalan untuk special event Hari Raya Idul Fitri

$$
P_{t+1}=1.5884\left[0.3 X_{t}+0.7 F_{t}\right]
$$

Peramalan untuk special event Hari Raya Idul Adha

$$
P_{t+1}=1.0024\left[0.3 X_{t}+0.7 F_{t}\right]
$$

2. Model untuk peramalan WES adalah sebagai berikut:

Pemulusan Keseluruhan

Pemulusan Trend

$$
L_{t}=0.3 \frac{X_{t}}{s_{t-s}}+0.7\left(L_{t-1}+T_{t-1}\right)
$$

Pemulusan Musiman

$$
T_{t}=0.1\left(L_{t}-L_{t-1}\right)+0.9 T_{t-1}
$$

$$
S_{t}=0.1 \frac{X_{t}}{L_{t}}+0.9 S_{t-s}
$$

Peramalan untuk 12 periode

$$
F_{t+12}=\left(L_{t}+p T_{t}\right) S_{t-s+12}
$$

Dari kedua model peramalan tersebut, model peramalan terbaik merupakan model Exponential Smoothing Event Based karena jumlah penumpang tiba di Pelabuhan Penyeberangan Gorontalo lebih dipengaruhi oleh special event sehingga memberikan nilai MAPE yang lebih kecil.

\section{KESIMPULAN}

Special event yang mempengaruhi jumlah penumpang yang tiba di Pelabuhan Penyeberangan Gorontalo adalah Hari Raya Idul Fitri dan Hari Raya Idul Adha. Dari perbandingan nilai MAPE hasil peramalan antara metode Exponential Smoothing Event Based dengan metode Winter's Exponential Smoothing maka metode yang lebih baik dalam meramalkan jumlah penumpang yang tiba adalah metode exponential smoothing event based karena memiliki nilai MAPE terkecil yakni $19.5916 \%$.

\section{DAFTAR PUSTAKA}

[1] "Biro Komunikasi dan Informasi Publik." [Online]. Available: http://dephub.go.id/post/read/menhub-puasdengan-fasilitas-barupenyeberangan-gorontalo, Diakses pada tanggal 3 April 2019, 2 Mei 2016

[2] Metro Siang., Jumlah Penumpang di Pelabuhan Gorontalo Naik 10\%, 3, https://m.metrotvnews.com/play/2017/04/15/686547. Diupload 15 April 2017, 12:00 WIB.

[3] Mimoza TV. Pemudik Mulai Ramaikan Pelabuhan Gorontalo, https://youtu.be/OorOd4lz4W8. Diupload 6 September 2017.

[4] Praditya, I. I., ASDP Indonesia Prediksi Penumpang Naik 5\% saat Libur Idul Adha, 3 Februari 2019, https://www.liputan6.com/bisnis/read/3077545/asdp-indonesia-prediksi-penumpang-naik-5-saat-libur-iduladha.

[5] Anggraeni, R., Jelang Natal, Pelabuhan Mulai Alami Lonjakan Penumpang, 3 Februari 2019, https://ekbis.sindonews.com/read/1365367/34/jelang-natal-pelabuhan-mulai-alami-lonjakan-penumpang1545626683.

[6] Robin, V. Tiket Habis, Penumpang Menginap di Pelabuhan Ferry, 3 Februari 2019, http://hargo.co.id/berita/tiket-habis-penumpang-menginap-di-pelabuhan-ferry.html.

[7] J. Hanke, E. Wiechan, and W. Dean, Business Forecasting, Edisi Kesembilan. United States of America: Pearson., 2014.

[8] S. Henifa, "Peramalan Penjualan Avtur dengan Mempertimbangkan Special Event,". Laporan Penelitian Tugas Akhir. Institut Teknologi Sepeuh Nopember, Surabaya, 2014. Available: http:digilib.its.ac.id/ITSpaper-12121140006026/33872. diakses pada tanggal 5 April 2019, 19 November 2014

[9] S. Makridakis, S. Wheelwright, and V. McGee, Metode dan Aplikasi Peramalan, Kedua. 1999. (Hal 123, 61).

[10] D. Montgomerry, C. Jennings, and M. Kulahci, Introduction to Time Series Analysis and Forecasting, Edisi Kedua. United States of America: Wiley, 2015.

[11] Suryaningtyas, "Peramalan Volume Penjualan Celana Panjang di Boyolali dengan Menggunakan Model Variasi Kalender," in Seminar Nasional Matematika dan Pendidikan Matematika, 2011, pp. 78-88. 